\title{
Fentanyl Intratekal Mencegah Menggigil Pasca Anestesi Spinal pada Seksio Sesaria
}

\author{
Intrathecal Fentanyl for Prevention of Post Anesthetic Shivering in Caesarean Section
}

\author{
Laksono RM, Isngadi \\ Laboratorium Anesthesiologi dan Terapi Intensif Rumah Sakit Umum Daerah Dr. Saiful Anwar Malang
}

\begin{abstract}
ABSTRAK
Menggigil pasca-anestesia dapat merugikan metabolisme tubuh. Salah satu cara yang diduga efektif secara farmakologis adalah dengan penambahan fentanyl intratekal saat dilakukan anestesi spinal. Penelitian eksperimental acak tersamar ganda dilakukan di kamar operasi RSU dr. Syaiful Anwar Malang untuk mengetahui efek fentanyl intratekal terhadap kejadian menggigil pada pasien seksio sesaria dengan anestesia spinal. Pasien yang menjalani operasi seksio sesaria sebanyak 40 orang, dibagi secara acak berdasarkan kelompok fentanyl $20 \mu \mathrm{g}$ ditambahkan pada bupivacaine $0,5 \% \mathrm{H} 10 \mathrm{mg}$ dan kelompok bupivacaine 0,5\% 10 mg murni. Setelah dilakukan anestesi spinal, pasien dievaluasi dan dicatat tiap 5 menit sampai menit ke 60. Kejadian dan intensitas menggigil diukur dengan skala Crossley dan Mahajan. Hasil kedua kelompok dibandingkan menggunakan uji $t$ tidak berpasangan, uji korelasi waktu pengukuran dan kejadian menggigil, uji fisher exact test, serta uji ANOVA dan Post Hoc untuk mengevaluasi masing-masing derajat menggigil. Hasil uji $t$ menunjukkan kejadian menggigil pada kelompok kontrol lebih tinggi daripada kejadian menggigil pada kelompok perlakuan $(p=0,002)$. Uji Fisher exact test menunjukkan hubungan signifikan $(p=0,006)$ antara perlakuan dengan kejadian menggigil. Kelompok kontrol risiko untuk mengalami kejadian menggigil bila dibandingkan kelompok perlakuan (OR=10,99; $95 \% \mathrm{Cl}=2,00-58,82$ ). Uji ANOVA menunjukkan perbedaan signifikan kejadian menggigil selama operasi antara kelompok kontrol dan perlakuan berdasarkan setiap derajat menggigil $(p=0,000)$. Efek samping berupa mual muntah ditemukan sesudah operasi pada $25 \%$ pasien dengan penambahan fentanyl. Dapat disimpulkan bahwa penambahan fentanyl intratekal dapat menurunkan risiko menggigil dengan efek samping mual dan muntah yang minimal
\end{abstract}

Kata Kunci: Anestesi spinal, fentanyl, post anesthetic shivering

\begin{abstract}
Post anesthetic shivering may cause distress in body metabolism. There are several pharmacological and non pharmacological means to overcome it. One mean which is considered pharmacologically effective is by adding intratechal fentanyl when conducting spinal anesthesia. This study was is identifying effect of intratechal fentanyl on incident of shivering in cesarian section patients with spinal anesthesia. Double blind randomized clinical trial carried out in operating teathers of dr. Saiful Anwar Hospital Malang. Forty cesarian section patients were divided into the addition of $20 \mu g$ fentanyl to $10 \mathrm{mg}$ bupivacaine 0,5\% $\mathrm{H}$ group and $10 \mathrm{mg}$ bupivacaine 0,5\% $\mathrm{H}$ alone group. Following spinal anasthesia, patients were evaluated and recorded every 5 minutes until 60 minutes for every shivering incident and degree of shivering with Crossley and Mahajan scale. The results of both groups were compared with unpaired test, regression test between recording time and shivering incident. Fisher exact test, ANOVA test, and Post Hoc test were used to evaluate each degree of shivering. Based on $t$ test, shivering incident in control group was higher than intervention group $(p=0,002)$. Control group has a risk to experience shivering than intervention group (OR=10,99; 95\% $\mathrm{Cl}=2,00-58,82)$. ANOVA test revealed a significant difference of shivering incident during surgery between control and intervention group based on degree of shivering $(p=0,000)$. The side effect (nausea and vomitus) was found after operation in $25 \%$ subjects in fentanyl group. It can be concluded that fentanyl intratechal administration has potential benefit for reducing post anesthetic shivering with minimal side effect.
\end{abstract}

Keywords: Fentanyl, post anesthetic shivering, spinal anesthesia

Jurnal Kedokteran Brawijaya, Vol. 27, No. 1, Februari 2012; Korespondensi: Laksono RM. Laboratorium Anesthesiologi dan Terapi Intensif Rumah Sakit Umum Dr. Saiful Anwar Malang. Jl. Jaksa Agung Suprapto No. 2 Malang Tel. (0341) 366242 Email: ristiawanm@yahoo.com 


\section{PENDAHULUAN}

Menggigil pada tindakan anestesia merupakan komplikasi yang umum dijumpai pada anestesia modern. Mekanisme terjadinya menggigil pada anestesia umum dan neuraksial hampir sama, yaitu terjadinya redistribusi panas tubuh dari kompartemen inti ke kompartemen perifer. Post Anesthetic Shivering (PAS) atau menggigil pasca-anestesia terjadi pada 5-65\% pasien yang menjalani anestesi umum dan lebih kurang $33-56,7 \%$ pasien dengan anestesia regional $(1,2)$.

Gangguan pengaturan suhu pada anestesia spinal lebih berat terjadi dibandingkan anestesia epidural. Efek vasodilatasi perifer pada anestesia spinal menyebabkan terjadinya perpindahan panas dari kompartemen sentral menuju kompartemen perifer sehingga menyebabkan hipotermi (3). Ketinggian blok spinal yang tercapai berhubungan langsung dengan ambang mengigil pasien sehingga semakin tinggi blok yang dihasilkan maka ambang menggigil pasien akan semakin rendah. Menggigil pasca-anestesia merupakan mekanisme kompensasi tubuh yang dapat juga menimbulkan efek samping yang merugikan $(4,5)$.

Menggigil pasca-anestesia dapat menyebabkan hal yang merugikan metabolisme tubuh, yaitu meningkatkan produksi $\mathrm{CO}_{2} 300-500 \%$ dan konsumsi $\mathrm{O}_{2}$ sampai dengan $200-400 \%$, yang diikuti dengan meningkatnya ventilasi semenit, pelepasan katekolamin, peningkatan denyut jantung, tekanan darah dan curah jantung. Keadaan tersebut menyebabkan nyeri pada luka operasi, peningkatan tekanan intrakranial, peningkatan tekanan intraokuler dan bahkan sebagian besar pasien mengemukakan bahwa pengalaman menggigil yang mereka alami jauh lebih buruk daripada nyeri pada luka operasi. Hal tersebut harus dihindari terutama pada pasien dengan penyakit jantung koroner atau dengan cadangan ventilasi yang terbatas (6).

Menggigil pasca-anestesi dapat diatasi dengan beberapa cara atau pendekatan. Pendekatan yang ditempuh dapat berupa non-farmakologis menggunakan konduksi panas yang dapat meningkatkan toleransi terhadap sistem regulasi tubuh terhadap hipotermia atau dapat juga menggunakan pendekatan farmakologis dengan obatobatan. Obat yang sering dipakai untuk mengatasi menggigil antara lain adalah pethidin, klonidin, dan tramadol. Obat-obat lain yang juga dapat digunakan untuk menurunkan atau mengurangi kejadian menggigil diantaranya ondansetron, neostigmin, dan fentanyl.

Fentanyl adalah agonis opioid sintetik yang berasal dari derivat phenyl piperidinel yang secara struktural terkait dengan meperidin. Obat ini sering digunakan sebagai analgesik intratekal dalam proses persalinan normal maupun pascaseksio. Selain itu, diketahui pula bahwa penambahan dosis kecil dari opioid lipofilik ini selama anestesia spinal dapat menyebabkan onset yang lebih cepat, blok yang lebih baik, dan waktu pemulihan fungsi motorik yang lebih cepat setelah pembedahan (7).

Hampir semua opioid diperkirakan mempengaruhi fungsi termoregulasi. Pada penelitian yang dilakukan oleh Techanivate (8) di India pada tahun 2005 menyimpulkan bahwa penambahan $20 \mathrm{~g}$ fentanyl pada $2,2 \mathrm{ml}$ bupivacain hiperbarik 0,5\% dengan 0,2 $\mathrm{ml}$ morfin 0,2 mg intratekal dapat menurunkan kejadian dan keparahan dari menggigil intraoperatif dan postoperatif sesudah anestesia spinal pada pasien yang menjalani seksio sesaria tanpa meningkatkan kejadian efek samping. Fentanyl intratekal dapat mencegah menggigil dengan menurunkan keparahan dari menggigil sepanjang tiga jam sesudah anestesia spinal dan menurunkan kejadian dari menggigil pada jam pertama termasuk saat sebelum bayi dilahirkan.

Opioid dan anestesia lokal menggunakan efek antinosiseptif yang dimiliki pada korda spinalis dengan mekanisme yang berbeda-beda. Fentanyl sebagai -agonis menggunakan efeknya melalui pembukaan kanal $\mathrm{K}^{+}$dan menurunkan influks dari $\mathrm{Ca}^{++}$, menyebabkan inhibisi pelepasan transmiter. Agonis juga memiliki efek postsinapsis langsung, yaitu menyebabkan hiperpolarisasi dan penurunan dari aktivitas neuronal. Walaupun penggunaan fentanyl sebagai anti-shivering tidak populer dibanding dengan pethidin, tetapi efek samping yang terjadi akibat pemberian fentanyl jauh lebih rendah bila dibandingkan dengan pethidin (9).

\section{METODE}

Penelitian ini merupakan uji klinis acak tersamar ganda untuk mengetahui efek penambahan fentanyl $20 \mu \mathrm{g}$ pada bupivakain 0,5\% $10 \mathrm{mg}$ intratekal terhadap penurunan kejadian dan intensitas menggigil pasca anestesia spinal. Penelitian dilakukan di Instalasi Gawat Darurat dan Instalasi Bedah Sentral RSUD Dr. Saiful Anwar Malang dalam kurun waktu 2 bulan. Subjek penelitian yang diikutsertakan pada penelitian ini adalah pasien yang menjalani operasi seksio sesaria berencana di Instalasi Bedah RSSA dan operasi SC emergensi di Instalasi Gawat Darurat RSUD Dr. Saiful Anwar Malang dengan anestesia spinal. Sampel didapatkan dengan consecutive sampling. Sampel yang dipergunakan total sebanyak 40 orang dengan 20 orang sampel diberi bupivacaine murni, dan 20 orang diberifentany/ dan bupivacaine.

Kriteria penerimaan sampel adalah pasien perempuan yang menjalani operasi seksio sesaria dengan anestesia spinal, berusia 18-40 tahun, tinggi badan $>150 \mathrm{~cm}$, berat badan sebelum hamil dengan BMI 20-30, status fisik ASA I-II, bersedia menjadi peserta penelitian dan menandatangani informed consent. Kriteria penolakan sampel adalah pasien yang mempunyai riwayat alergi fentanyl. Kriteria putus uji mencakup timbul penyulit seperti alergi sistemik, reaksi anafilaktik, dan henti jantung, terjadi pendarahan $>20 \%$, jika operasi berlangsung $<20$ menit atau $>120$ menit, ketinggian blok anestesia >vertebra torakal 5, dan gagal spinal.

Alat yang digunakan meliputi alat monitor tekanan darah non invasif otomatik (dash 2000/3000), alat monitor EKG (dash 2000/3000), alat monitor denyut oksimetri (dash 2000/3000), alat pengukur suhu timpani (omron/apex dengan kalibrasi), pencatat waktu (stopwatch), alat tulis dan formulir penelitian dan regimen spinal. Bahan yang digunakan: cairan ringer laktat dan koloid, fentanyl $20 \mu \mathrm{g}$ (tidak diencerkan) dan bupivacaine 0,5\% heavy.

Semua pasien diberikan premedikasi. Dilakukan randomisasi sederhana menjadi dua kelompok yaitu kelompok yang mendapat fentanyl $20 \mu \mathrm{g}$ intratekal atau kelompok kontrol. Sebelum dilakukan anestesia spinal, dilakukan preloading dengan ringer laktat $10 \mathrm{cc} / \mathrm{kg}$ dalam 15 menit. Suhu kamar operasi dipertahankan antara $20^{\circ} \mathrm{C}$ - 
$23^{\circ} \mathrm{C}$ dengan mengatur suhu $A C$ dan suhu ruangan dipantau melalui termometer ruangan.

Data penderita (tekanan darah, frekuensi denyut nadi, suhu timpani yang diukur setiap 5 menit dicatat dan dikumpulkan pada formulir pengumpulan data, kemudian dilakukan tabulasi data. Hasil penelitian untuk karakteristik subjek penelitian dilakukan uji normalitas sebaran data dengan Saphiro Wilk Test. Secara deskriptif kemudian dilakukan pengukuran homogenitas sampel penelitian dengan melihat umur, Body Mass Index (BMI), dan suhu membran timpani sebelum dilakukan spinal anestesi yaitu dengan menggunakan t-test, sedangkan berat badan dan tinggi badan sampel penelitian dengan menggunakan Mann Whitney U-test karena sebaran data tidak normal. Dilakukan pencatatan kejadian menggigil pada kedua kelompok dan disajikan dalam prosentase yang kemudian dilakukan $t$ test independen untuk mengetahui perbedaan kejadian menggigil pada kelompok kontrol dan perlakuan. Dari data kejadian menggigil pada kedua kelompok selanjutnya dilakukan uji regresi untuk mengetahui pengaruh (efek) pemberian perlakuan terhadap kejadian menggigil pada pasien. Dilakukan pengumpulan data kejadian menggigil berdasarkan derajat menggigil yang terjadi kemudian dari data tersebut dilakukan uji ANOVA dan uji Post Hoc untuk menilai masing-masing derajat menggigil yang terjadi. Dilakukan evaluasi efek samping yang terjadi terhadap penggunaan fentany/ intratekal antara kedua kelompok.

\section{HASIL}

Secara deskriptif, hasil penelitian menunjukkan peningkatan kejadian menggigil dengan semakin meningkatnya waktu pada kedua kelompok (Tabel 1). Prosentase kejadian menggigil didapatkan lebih tinggi pada kelompok yang tidak diberikan fentanyl yang mencapai $90 \%$ sejak menit ke 45 . Kelompok dengan pemberian fentanyl menunjukkan prosentase kejadian menggigil maksimal sebesar $45 \%$ pada menit ke empat puluh. Data ini sekaligus menunjukkan tanpa pemberian fentanyl kejadian menggigil timbul lebih cepat dan lebih banyak. Hasil uji t menunjukkan bahwa kejadian menggigil pada pemberian fentanyl secara signifikan lebih rendah (mean $62,08 \%, p=0,002$ ) dibandingkan tanpa pemberian fentanyl (mean kejadian menggigil=25,17\%).

Tabel 1. Kejadian mengigil selama operasi berdasarkan waktu pengukuran

\begin{tabular}{lcc}
\hline Waktu Pengukuran & Kelompok Kontrol & $\begin{array}{c}\text { Kelompok } \\
\text { Perlakuan }\end{array}$ \\
\hline Menit ke-5 & $15 \%$ & $0 \%$ \\
Menit ke-10 & $15 \%$ & $0 \%$ \\
Menit ke-15 & $20 \%$ & $10 \%$ \\
Menit ke-20 & $50 \%$ & $10 \%$ \\
Menit ke-25 & $65 \%$ & $20 \%$ \\
Menit ke-30 & $65 \%$ & $25 \%$ \\
Menit ke-35 & $70 \%$ & $30 \%$ \\
Menit ke-40 & $85 \%$ & $45 \%$ \\
Menit ke-45 & $90 \%$ & $45 \%$ \\
Menit ke-50 & $90 \%$ & $45 \%$ \\
Menit ke-55 & $90 \%$ & $45 \%$ \\
Menit ke-60 & $90 \%$ & $45 \%$ \\
Keseluruhan & $90 \%$ & $45 \%$ \\
\hline
\end{tabular}

Analisis korelasi menunjukkan ada hubungan positif yang kuat antara waktu pengukuran dengan kejadian menggigil selama operasi pada kelompok kontrol $(r=0,939 ; p=0,000)$ maupun pada kelompok dengan pemberian fentanyl $(r=0,932 ; p=0,000)$. Semakin lama waktu pengamatan semakin besar prosentase kejadian menggigil dengan prosentase kejadian yang lebih rendah pada pemberian fentanyl.

Dari uji Fisher exact test menunjukkan terdapat hubungan yang signifikan $(p=0,006)$ antara pemberian fentanyl dengan kejadian menggigil (Tabel 2). Kelompok yang tidak mendapatkan fentanyl merupakan faktor risiko kejadian menggigil bila dibandingkan kelompok yang mendapat fentanyl (OR=10,99; 95\% Cl= 2,00-58,82).

Tabel 2. Tabulasi silang kejadian menggigil dan perlakuan

\begin{tabular}{lllll}
\hline \multirow{4}{*}{ Tidak mengigil } & & \multicolumn{2}{l}{ Kelompok } & Total \\
\cline { 3 - 3 } & & kontrol & Perlakuan & \\
\multirow{3}{*}{ Menggigil } & Jumlah & 2 & 11 & 13 \\
& Prosentase & $10,0 \%$ & $55,0 \%$ & $32,5 \%$ \\
\multirow{2}{*}{ Total } & Jumlah & 18 & 9 & 27 \\
& Prosentase & $90,0 \%$ & $45,0 \%$ & $67,5 \%$ \\
& Jumlah & 20 & 20 & 40 \\
& Prosentase & $100,0 \%$ & $100,0 \%$ & $100,0 \%$ \\
\hline
\end{tabular}

Secara keseluruhan bila dikaji berdasarkan derajat menggigil dan waktu, kejadian tidak menggigil lebih banyak ditemukan pada kelompok perlakuan. Kejadian menggigil derajat 1 lebih awal dialami oleh kelompok kontrol daripada kelompok perlakuan, begitu pula dengan derajat menggigil 2. Berdasarkan waktu pengukuran dibandingkan dengan kelompok dengan pemberian fentanyl, kelompok kontrol lebih banyak mengalami kejadian menggigil derajat 3 . Kejadian mengigil derajat 4 jarang terjadi bila dibandingkan dengan derajat yang lain, kejadian menggigil derajat 4 lebih awal terjadi pada kelompok perlakuan (Tabel 3). Hasil uji ANOVA menunjukkan bahwa kejadian menggigil selama operasi menunjukkan berbeda signifikan berdasarkan derajat menggigil $(p=0,000)$, serta berdasarkan interaksi antara kelompok dan derajat mengggigil $(p=0,000)$. Interaksi dapat diartikan bahwa ada perbedaan kejadian menggigil selama operasi yang signifikan antara kelompok kontrol dan pemberian fentanyl disetiap derajat menggigil. Jika hanya dibedakan berdasarkan kelompoknya saja, justru tidak ada perbedaan kejadian menggigil selama operasi yang signifikan $(p=0,975)$.

Efek samping yang mungkin terjadi pada pemberian fentanyl adalah mual dan muntah. Hasil penelitian menunjukkan tidak ditemukan kejadian muntah pada kedua kelompok selama operasi. Pengamatan pada saat post operasi ditemukan $25 \%$ pasien pada kelompok dengan penambahan fentany/mengalami muntah.

\section{DISKUSI}

Hasil penelitian menunjukkan bahwa dengan adanya perlakuan, yaitu penambahan fentany/ intratekal, kejadian menggigil yang terjadi berkurang seiring dengan waktu pengukuran. Dapat disimpulkan bahwa kejadian menggigil yang akan bertambah seiring berjalannya waktu saat 
Tabel 3. Distribusi frekuensi derajat kejadian menggigil selama operasi berdasarkan waktu pengukuran

\begin{tabular}{|c|c|c|c|c|c|c|c|c|c|c|}
\hline \multirow[t]{2}{*}{$\begin{array}{l}\text { Waktu } \\
\text { Pengukuran }\end{array}$} & \multicolumn{2}{|c|}{ Tidak menggigil } & \multicolumn{2}{|c|}{ Menggigil Derajat 1} & \multicolumn{2}{|c|}{ Menggigil Derajat 2} & \multicolumn{2}{|c|}{ Menggigil Derajat 3} & \multicolumn{2}{|c|}{ Menggigil Derajat 4} \\
\hline & + & - & + & - & + & - & + & - & + & - \\
\hline Menit ke-5 & $100 \%$ & $85 \%$ & 0 & $10 \%$ & 0 & 0 & 0 & $5 \%$ & 0 & 0 \\
\hline Menit ke-10 & $100 \%$ & $85 \%$ & 0 & $5 \%$ & 0 & $5 \%$ & 0 & $5 \%$ & 0 & 0 \\
\hline Menit ke-15 & $90 \%$ & $80 \%$ & $5 \%$ & $10 \%$ & $5 \%$ & $5 \%$ & 0 & $5 \%$ & 0 & 0 \\
\hline Menit ke-20 & $90 \%$ & $50 \%$ & $5 \%$ & $30 \%$ & $5 \%$ & $10 \%$ & 0 & $10 \%$ & 0 & 0 \\
\hline Menit ke-25 & $80 \%$ & $35 \%$ & $15 \%$ & $30 \%$ & $5 \%$ & $15 \%$ & 0 & $20 \%$ & $5 \%$ & 0 \\
\hline Menit ke-30 & $75 \%$ & $35 \%$ & $15 \%$ & $30 \%$ & $5 \%$ & $10 \%$ & 0 & $25 \%$ & $5 \%$ & 0 \\
\hline Menit ke-35 & $70 \%$ & $30 \%$ & $20 \%$ & $25 \%$ & $5 \%$ & $20 \%$ & 0 & $25 \%$ & $5 \%$ & 0 \\
\hline Menit ke-40 & $55 \%$ & $15 \%$ & $20 \%$ & $20 \%$ & $20 \%$ & $45 \%$ & 0 & $15 \%$ & $5 \%$ & $5 \%$ \\
\hline Menit ke-45 & $55 \%$ & $10 \%$ & $20 \%$ & $15 \%$ & $15 \%$ & $55 \%$ & $5 \%$ & $15 \%$ & $5 \%$ & $5 \%$ \\
\hline Menit ke-50 & $55 \%$ & $10 \%$ & $20 \%$ & $5 \%$ & $15 \%$ & $40 \%$ & $5 \%$ & $40 \%$ & $5 \%$ & $5 \%$ \\
\hline Menit ke-55 & $55 \%$ & $10 \%$ & $15 \%$ & $5 \%$ & $15 \%$ & $30 \%$ & $15 \%$ & $50 \%$ & 0 & $5 \%$ \\
\hline Menit ke-60 & $55 \%$ & $10 \%$ & $15 \%$ & $5 \%$ & $20 \%$ & $30 \%$ & $10 \%$ & $50 \%$ & 0 & $5 \%$ \\
\hline
\end{tabular}

Keterangan:

+ : kelompok perlakuan

- : kelompok kontrol

dilakukan anestesi spinal dapat diturunkan kejadiannya bila dilakukan penambahan fentanyl intratekal saat dilakukan anestesi spinal. Pada penelitian oleh Techanivate et al (6) menyimpulkan bahwa penambahan 20 g fentanyl pada 2,2 $\mathrm{ml}$ bupivacain hiperbarik 0,5\% dengan $0,2 \mathrm{ml}$ morfin $0,2 \mathrm{mg}$ intratekal dapat menurunkan kejadian dan keparahan dari menggigil intraoperatif dan postoperatif sesudah anestesia spinal pada pasien yang menjalani seksio sesaria tanpa meningkatkan kejadian efek samping. Fentanyl intratekal dapat mencegah menggigil dengan menurunkan keparahan dari menggigil sepanjang tiga jam sesudah anestesia spinal dan menurunkan kejadian dari menggigil pada jam pertama termasuk saat sebelum bayi dilahirkan. Penurunan kejadian menggigil pada penelitian oleh Techanivate et al (6) diduga dapat disebabkan oleh efek fentanyl yang ditambahkan pada ruang subarachnoid pada termoregulator dan dapat mempengaruhi input termal aferen pada medulla spinalis. Karena sifatnya yang lipofilik, fentanyl yang berukuran kecil mencapai otak melalui jalur serebrospinal dan tidak akan mengganggu kontrol termoregulasi oleh hipotalamus. Kerugian dari menurunnya efek menggigil adalah meningkatnya risiko dari hipotermia karena temperatur inti yang rendah tidak dapat menginisiasi respon protektif otonom.

Arkilic CF et al (10) mengemukakan bahwa anestesi neuroaksial mengganggu pusat pengaturan termoregulasi otonom sesuai dengan tinggi atau penyebaran blok saraf yang terjadi. Hipotermia yang terjadi pada anestesi neuroaksial disebabkan oleh tiga mekanisme, yaitu fase pertama: redistribusi panas tubuh, fase kedua: kehilangan panas yang melebihi produksi panas, dan fase ketiga: inhibisi pusat regulasi suhu. Bila dianalisis, kurang dari 30 menit pertama adalah fase redistribusi yang mana terjadi distribusi panas yang besar dari inti tubuh ke perifer yang menyebabkan terjadinya hipotermia. Anestesi spinal maupun fentanyl sendiri dapat menurunkan ambang menggigil pasien sehingga walaupun terjadi hipotermia, tetapi tidak sampai melewati ambang menggigil yang turun karena efek fentanyl. Pada fase ini dapat dijelaskan mengapa pada menit-menit awal selama anestesi spinal, terutama pada menit ke-5 sampai dengan menit ke-10, tidak terdapat kejadian menggigil pada kelompok perlakuan.

Pada waktu lebih dari 30 menit dapat dikatakan masuk pada fase kedua yang mana terjadi kehilangan panas yang melebihi produksi panas. Pada fase ini penurunan suhu masih terjadi walaupun dengan grafik yang linear dan pada satu titik akan melewati ambang menggigil. Anestesi spinal akan menghambat pembentukan panas tubuh, terutama di bawah bagian yang terblok. Faktor-faktor yang mempengaruhi kejadian hipotermia maupun menggigil pada fase ini, antara lain, suhu ruang operasi, lama operasi, dan morfometri pasien. Semakin rendah suhu ruang operasi, semakin panjang waktu operasi dan semakin tipis lapisan lemak tubuh pasien, akan menyebabkan kejadian menggigil yang semakin besar (11). Pada keadaan ini pemberian fentanyl $20 \mu \mathrm{g}$ intratekal ternyata tetap memberikan efek yang bermakna dibanding dengan kontrol. Dengan menggunakan analisis cross tabulation, terlihat bahwa anastesi tanpa fentanyl merupakan faktor risiko terjadinya menggigil pasca anastesi.

Dapat disimpulkan pemberian fentanyl $20 \mu \mathrm{g}$ intratekal terbukti secara bermakna menurunkan kejadian menggigil pascaanestesi spinal pada pasien yang dilakukan seksio sesaria dengan efek samping minimal. Fentanyl $20 \mu \mathrm{g}$ intratekal terbukti secara bermakna mengurangi derajat atau intensitas menggigil pasca anestesi spinal pada pasien yang dilakukan seksio sesaria. Pasien seksio sesaria yang dilakukan anestesi spinal dengan penambahan fentanyl intratekal $20 \mu \mathrm{g}$ mempunyai peluang atau risiko 11 kali lebih rendah daripada pasien yang dilakukan anestesi spinal tanpa penambahan fentany/ intratekal.

\section{UCAPAN TERIMA KASIH}

Penulis mengucapkan terima kasih kepada dr. Gunung Mahameru, Sp.An.KIC (Alm), dan dr. Feza atas dukungan dan bantuan selama penelitian dan penulisan ini. 


\section{DAFTAR PUSTAKA}

1. Buggy DJ and Crossley AWA. Thermoregulation, Mild Peri-operatif Hypothermia and Postanesthetic Shivering. British Journal of Anaesthesia. 2000; 84(5): 615-628.

2. Alfonsi P. Postanaesthetic Shivering. Epidemiology, Pathophysiology and Approaches to Prevention and Management. Minerva Anastesiologica. 2003; 69(5): 438-442.

3. Sessler DI. Post Anesthesia Shivering. In: Miller RD (Ed). Anesthesia 4th edition. New York: Churchil Livingstone Inc.; 1994; p. 1363-1382.

4. Leslie K and Sessler DI. Reduction in the Shivering tresholds proportional to spinal block height. Anesthesiology. 1996; 84(6): 1327-1331.

5. Lenhardt R. The Effect of Anesthesia on Body Temperature Control. Frontiers of Bioscience. 2010; 2: 1145-1154.
6. Carli F and Mac Donald IA. Perioperatif in Advertent Hypothermia: What do We Need to Prevent? British Journal of Anaesthesia. 1996; 76(5): 601-603.

7. Katzung BZ. Basic and Clinical Paharmacology. 10th edition. New York: McGraw Hill; 2007.

8. Techanivate A, Rodanant O, Tachawattanawisal W, and Somsiri T. Intrathecal Fentanyl for Prevention of Shivering in Caesarean Section. Journal of the Medical Association of Thailand. 2005; 88(9): 1214-1221.

9. Bailey PL and Stanley TH. Intra Venous Opioid Anesthetic. In: Miller RD (Ed). Anesthesia 4th edition. New York: Churchill Livingstone Inc.; 1994; p. 291-387.

10. Arkilic CF, Akca O, Taguchi A, Sessler DI, and Kurz A. Temparature Monitoring and Management During Neuraxial Anesthesia; An Observational Study. Anesthesia and Analgesia. 2000; 91(3): 662-666.

11. Kurz A. Thermal Care in the Perioperative Period. Best Practice and Research Clinical Anaesthesiology. 2008; 22(1): 39-62. 